\title{
Stimulation of cAMP signalling allows isolation of clonal pancreatic precursor cells from adult mouse pancreas
}

\author{
T. Yamamoto $\cdot$ E. Yamato $\cdot$ H. Taniguchi $\cdot$ M. Shimoda $・$ \\ F. Tashiro • M. Hosoi • T. Sato • S. Fujii • J.-I. Miyazaki
}

Received: 11 May 2006 / Accepted: 20 May 2006 / Published online: 8 August 2006

(C) Springer-Verlag 2006

\begin{abstract}
Aims/hypothesis Duct cells of the pancreas are thought to include latent progenitors of islet endocrine cells that can be induced to differentiate by appropriate morphogens. Here we developed a method for isolating pancreatic ductal epithelial cells from adult mice that overcomes the shortcomings of previous methods.

Materials and methods Pancreatic ductal cells were grown in serum-free DMEM/F12 medium in the presence of cholera toxin or 8-bromo-cyclic adenosine monophosphate, which is known to be an intracellular cAMP generator. Single cell cloning was performed by limiting dilution in serum-free medium.

Results The isolated clonal cells expressed high levels of cytokeratin and Ipfl (formerly known as $P d x-1$ ). Adenovirus-mediated expression of ngn3 (also known as Neurog3) and Ptfla in these cells induced expression of insulin and somatostatin, and of carboxypeptidase A, respectively. Furthermore, albumin production was induced by dexamethasone or by long-term culture in serum-containing medium. Conclusions/interpretation Stimulation of the cAMP-dependent signalling allowed us to isolate clonal pancreatic ductal cells from adult mice. These cells are able to partially differentiate into endocrine cells, exocrine cells and

T. Yamamoto $\cdot$ E. Yamato $\cdot$ H. Taniguchi $\cdot$ M. Shimoda $\cdot$

F. Tashiro $\cdot$ J.-I. Miyazaki $(\bowtie)$

Division of Stem Cell Regulation Research, G6,

Osaka University Graduate School of Medicine,

2-2 Yamadaoka, Suita,

Osaka 565-0871, Japan

e-mail: jimiyaza@nutri.med.osaka-u.ac.jp

T. Yamamoto $\cdot$ M. Hosoi $\cdot$ T. Sato $\cdot$ S. Fujii

Department of Metabolism and Endocrinology,

Osaka City General Hospital,

Osaka, Japan
\end{abstract}

hepatocyte-like cells and are therefore considered to have the characteristics of endodermal progenitor cells.

Keywords cAMP. Cholera toxin - Cytokeratin · Insulin . Ngn3 $\cdot$ Pancreatic ductal cells $\cdot$ Pdx-1 $\cdot$ Serum-free

$\begin{array}{ll}\text { Abbreviations } \\ \text { AdV } & \text { adenovirus vector } \\ \text { 8-Br-cAMP } & \text { 8-bromo-cyclic adenosine monophosphate } \\ \text { CAII } & \text { carbonic anhydrase II } \\ \text { CTx } & \text { cholera toxin } \\ \text { FBS } & \text { fetal bovine serum } \\ \text { KGF } & \text { keratinocyte growth factor } \\ \text { Pdx-1 } & \text { pancreatic and duodenal homeobox 1 } \\ & \text { (encoded by the Ipfl gene) } \\ \text { PPPD } & \text { Pdx-1-positive pancreatic duct-derived }\end{array}$

\section{Introduction}

It was thought that islet endocrine cells were predominantly derived from the precursor cells that reside among pancreatic epithelial duct cells or duct-associated cells both during embryonic development and later in life; islet cell neogenesis from ducts has been observed in experimental injury models in rats $[1,2]$ and in transgenic mice overexpressing certain growth factors or cytokines [3, 4]. Furthermore, recent studies have demonstrated that isolated murine and human pancreatic ductal cells could be directed to differentiate into glucose-responsive insulin-producing cells in vitro $[5,6]$.

Cultures of pancreatic duct cells have been established using cells from several animals: mice [7, 8], rats [9], hamsters [10], cattle [11], guinea-pigs [12] and humans 
[13]. Various basal media enriched with a wide variety of supplements have been used for these duct cell cultures. However, the experimental utility of pancreatic duct cell culture systems has been hampered by difficulties encountered in eliminating fibroblast contamination and by the limited survival in culture. Furthermore, these culture systems gave rise to heterogeneous cell populations and made it difficult to analyse the molecular mechanisms regulating ductal cell differentiation.

Here, to further investigate the mechanisms of the proliferation of pancreatic duct cells from adult mice and to evaluate the latent abilities of the duct cells to differentiate into other cells morphologically and biochemically, we developed a method for the isolation and cultivation of Pdx1-positive pancreatic duct-derived (PPPD) cells from normal adult mice without genetic manipulation.

\section{Materials and methods}

Isolation of pancreatic ductal cells and single-cell cloning

Pancreas tissue was obtained from 20-week-old normal adult C57BL/6J mice (Clea Japan, Tokyo, Japan) and digested with collagenase type XI (Sigma-Aldrich, Saint Louis, MO, USA). After repeated washes with cold Hanks' balanced salt solution (Invitrogen, Carlsbad, CA, USA) containing 2-mercaptoethanol (Wako, Osaka, Japan), fractions enriched with pancreatic ductal fragments were passed through a stainless-steel mesh sieve with $850-\mu \mathrm{m}$ pores. The pancreatic ductal fraction trapped on the sieve was cultured on a tissue culture plate in CMRL-1066 medium (Sigma-Aldrich) containing 10\% fetal bovine serum (FBS; Cansera International, ON, Canada), $100 \mathrm{ng} / \mathrm{ml}$ cholera toxin (CTx; Sigma-Aldrich), and Antibiotic-Antimycotic $(100 \mathrm{U} / \mathrm{ml}$ of penicillin, $100 \mu \mathrm{g} / \mathrm{ml}$ of streptomycin and $250 \mathrm{ng} / \mathrm{ml}$ of amphotericin B; Invitrogen). To reduce the fibroblast contamination in the primary culture, the medium containing ductal fragments was transferred to another plate $2 \mathrm{~h}$ after the initial plating. After 4 days, the culture medium was changed to serum-free medium consisting of 1:1 mixture of DMEM (Sigma-Aldrich) and Ham's F-12 (Invitrogen) medium supplemented with $100 \mathrm{ng} / \mathrm{ml} \mathrm{CTx}$, $5 \mu \mathrm{g} / \mathrm{ml}$ insulin (Sigma-Aldrich), $5 \mu \mathrm{g} / \mathrm{ml}$ transferrin (Sigma-Aldrich), $5 \mathrm{ng} / \mathrm{ml}$ sodium selenite (Sigma-Aldrich), $0.2 \%$ bovine serum albumin (Sigma-Aldrich), $25 \mathrm{ng} / \mathrm{ml}$ keratinocyte growth factor (KGF; Sigma-Aldrich), and Antibiotic-Antimycotic. The culture was incubated at $37^{\circ}$ $\mathrm{C}$ in a humidified $5 \% \mathrm{CO}_{2}$ and $95 \%$ air atmosphere, and the medium was changed every 2 or 3 days. After more than 40 days in serum-free medium, first passage was performed. The resulting cells showed stable growth in serum-free medium for more than 1 year. To experimentally induce hepatocyte lineage, 10\% FBS, CTx and AntibioticAntimycotic were included. Subcloning of the ductal cells was performed by limiting dilution in serum-free DMEM/ F12 medium. Dissociated cells were placed at $1-10$ cells/ $0.1 \mathrm{ml}$ per well in a 96-well plate.

\section{Electron microscopy}

Ultrastructural studies were performed on cultured cells attached as a monolayer in tissue culture dishes after four passages. For electron microscopy, cells were fixed for $3 \mathrm{~h}$ with $2.5 \%$ glutaraldehyde, and then post-fixed with $1 \%$ osmium tetroxide. After overnight dehydration in graded ethanol solutions and propylene oxide, the cells were embedded in a mixture of Epon-Araldite. Thin sections (approximately $80 \mathrm{~nm}$ ) were cut using a Reichert Ultracut OM-U4 microtome (Microm, Walldorf, Germany) and were stained with uranyl acetate and lead citrate. Transmission electron microscopy was carried out using a Hitachi H-7100 electron microscope (Hitachi Hi-technologies, Tokyo, Japan).

\section{Cell proliferation analysis}

Cell proliferation was assessed by counting the number of cells per colony. 8-Bromo-cyclic adenosine monophosphate (8-Br-cAMP; Biomol, Plymouth Meeting, PA, USA), PD98059 (Sigma-Aldrich), and KT5720 (Sigma-Aldrich) were respectively added to serum-free DMEM/F12 medium at an optimal concentration.

\section{RT-PCR}

Total RNA was extracted from cultured cells by the acid guanidinium-phenol-chloroform method. The cDNA was prepared from total RNA using a ReverTra Ace- $\alpha$ kit (Toyobo, Tokyo, Japan) with oligo-dT primers according to the manufacturer's instructions. The primer sequences and PCR conditions used for RT-PCR were previously described [14]. PCR was performed with Taq DNA polymerase (Promega, Madison, WI, USA) and within the log phase of the reaction (25-35 cycles). For quantitative estimation of Ins 2 and GAPDH mRNA, real-time RT-PCR was performed on the ABI PRISM 7700 Sequence Detector (Applied Biosystems, Foster City, CA, USA) using SYBR Premix Ex Taq (TaKaRa Bio, Otsu, Japan). The relative amount of Ins2 mRNA was determined using GAPDH mRNA as a standard. Amplification conditions comprised initial denaturation at $95^{\circ} \mathrm{C}$ for $10 \mathrm{~s}$, followed by 40 cycles of denaturation at $95^{\circ} \mathrm{C}$ for $5 \mathrm{~s}$ and annealing and extension at $60^{\circ} \mathrm{C}$ for $30 \mathrm{~s}$. The primer sequences for Ins 2 were: forward, 5'-GATCCGCTACAATCAAAAACCAT-3'; reverse, 5'ATCCACAGGGCCATGTTGAA-3'. Those for GAPDH 
were: forward, 5'-TGTGTCCGTCGTGGATCTGA-3'; reverse, 5'-CCTGCTTCACCACCTTCTTGA-3'.

Immunocytochemical staining

Monolayer cultures of epithelial cells were washed four times with PBS, fixed for $15 \mathrm{~min}$ in 4\% paraformaldehyde (PFA), and then incubated with blocking reagent (Roche, Mannheim, Germany). Immunofluorescence staining was performed using the following primary antibodies: mouse anti-human pancytokeratin monoclonal antibody (dilution 1:200, SigmaAldrich), rabbit anti-rat Pdx-1 polyclonal antibody (1:200, gift from Y. Kajimoto, Osaka University, Osaka, Japan), rabbit anti-mouse albumin polyclonal antibody (Biogenesis, Poole, UK), and goat anti-mouse HNF3 $\beta$ polyclonal antibody (Santa Cruz Biotechnology, Santa Cruz, CA, USA). The secondary antibodies were Alexa 568-conjugated goat antimouse IgG antibody, Alexa 568-conjugated donkey anti-goat IgG antibody and Alexa 488-conjugated goat anti-rabbit IgG antibody (Molecular Probes, Eugene, OR, USA). Alexa 568 was excited at $543 \mathrm{~nm}$ and Alexa 488 at $488 \mathrm{~nm}$, using the Leica confocal laser scanning microscope system TCS SP2 (Leica Microsystems, Wetzlar, Germany).

Western blot analysis

Duct-derived cells and MIN6 cells were lysed in detergent lysis buffer. A total of $20-\mu \mathrm{g}$ protein extracts was separated by SDS-PAGE, then electrotransferred onto an Immobilon P membrane (Millipore, Bedford, MA, USA). The membrane was incubated with rabbit anti-rat $\mathrm{Pdx}-1$ polyclonal antibody (dilution 1:1,000). After incubation with horseradish-peroxidase-conjugated goat anti-rabbit IgG second antibody (New England Biolabs, Beverly, MA, USA), the membrane was subjected to an ECL detection system (Amersham Biosciences, Piscataway, NJ, USA).

Construction of adenoviral vector expressing mouse ngn3 and Ptfla

A full-length cDNA of mouse ngn3 (also known as Neurog3) was cloned from mouse brain cDNA, and that of mouse Ptfla was cloned from mouse pancreas cDNA. Adenovirus vectors ( $\mathrm{AdVs}$ ) expressing these cDNAs were generated as described previously [15] (Fig. 3a). Ductderived cells were infected with control adenovirus vector (AdV-EGFP), AdV-ngn3, or AdV-Ptfla at a multiplicity of infection (MOI) of 50 for $2 \mathrm{~h}$ at $37^{\circ} \mathrm{C}$.

Induction of hepatocyte genes by dexamethasone

Duct-derived cells were seeded onto a six-well tissue culture plate in serum-free DMEM/F12 medium and cultured for 2 weeks with different concentrations of dexamethasone (Sigma-Aldrich).

Statistical analysis

We carried out descriptive statistics and analysis of variance (ANOVA) followed by two-tailed Student's $t$-test using Statsview software (Abacus Concepts, Berkeley, CA, USA).

\section{Results}

Culture of pancreatic cells and analysis of cell proliferation

The duct fraction was cultured in CMRL-1066 medium containing FBS for 4 days. After the first passage, the cells were cultured in serum-free DMEM/F12 containing CTx, $\mathrm{KGF}$, insulin, transferrin and sodium selenite. Over the subsequent 40 days, only a fraction of the adherent cells expanded, while the spindle-shaped fibroblasts stopped proliferating and gradually disappeared. After second passage, KGF was removed because it was no longer required for cell proliferation. The resulting adherent cells were maintained for more than a year under serum-free conditions.

These cells could proliferate only in the presence of CTx, which is known to be an intracellular cAMP generator (Fig. 1a,b) [16]. As shown in Fig. 1c, the addition of 8-BrcAMP, a membrane-permeable cAMP analogue, into serum-free medium instead of CTx also stimulated the cell proliferation. The effect of CTx on the proliferation of ductal epithelial cells was significantly inhibited by the addition of PD98059, a mitogen-activated protein kinase (MAPK) inhibitor, or KT5720, a protein kinase A (PKA) inhibitor. Taken together, activation of the cAMP-dependent signalling pathway appeared to be essential for the pancreatic cell proliferation.

Morphology of pancreatic ductal epithelial cells

These cells contained a large, well-defined nucleus with prominent nucleoli and a relatively small volume of cytoplasm, and their cytoplasm was positively immunostained with an anti-pancytokeratin antibody (Fig. 2a).

Ultrastructural studies of the pancreatic precursor cells demonstrated typical features of the epithelium (Fig. 2bi). The plasma membrane possessed specialisations, including numerous surface microvilli, and exhibited close interdigitations with tight junctions (Fig. 2bii and biii). One or two nuclei were eccentrically located and irregularly shaped, displaying clumping of the chromatin in the region of the nuclear membrane and some nucleoli (Fig. 2biv). None of 
a
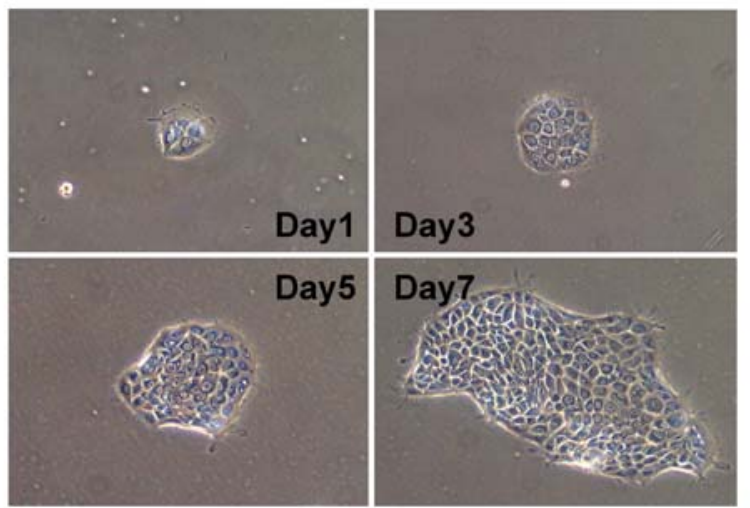

C

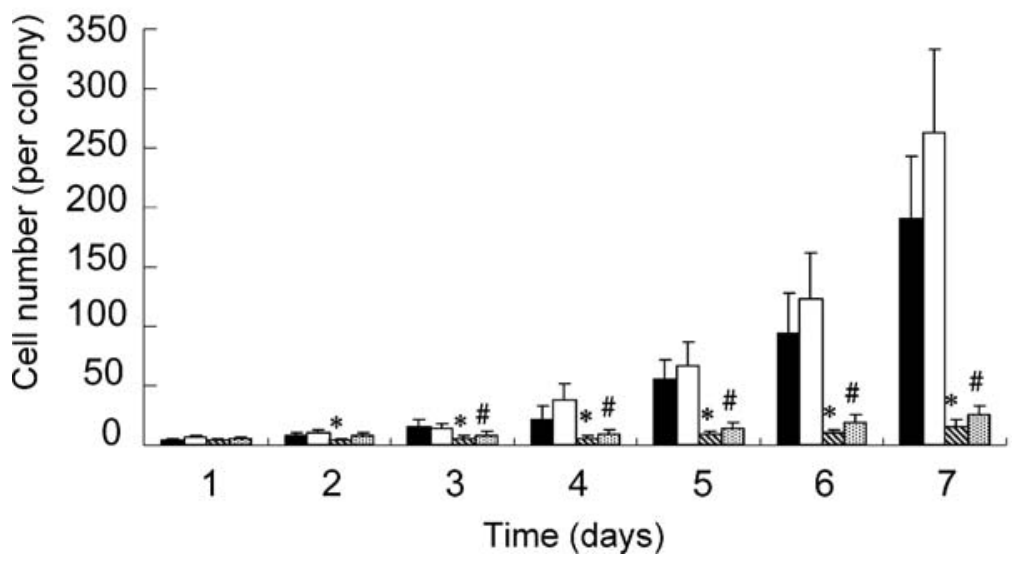

Fig. 1 Analysis of the mechanism for PPPD cell proliferation in serum-free medium. a Phase-contrast micrographs show the increase of the cell number in each colony cultured with CTx. b Microscopic observation of the growth of PPPD cells cultured in serum-free medium with (closed bar; $n=10$ ) or without (open bar; $n=5) 100 \mathrm{ng}$ / ml CTx. ${ }^{*} p<0.005$ by two-tailed Student's $t$-test. c The addition of

the cells exhibited the well-developed secretory granules that are characteristic of acinar or islet cells.

\section{Characterisation of isolated pancreatic cells}

Isolated pancreatic cells at passage 3 were analysed for their gene expression pattern. A high expression of Krtl-19 (which encodes cytokeratin 19) and Car2 (which encodes carbonic anhydrase II), markers of epithelial cells, was specifically detected. No gene expression of endocrine and exocrine pancreas marker genes was detected. These results, taken together with ultrastructural studies, suggest that these pancreatic cells were derived from pancreatic ductal epithelial cells and did not contain any islet or acinar cells. These pancreatic duct-derived cells also expressed Ipf1 (formerly known as Pdx-1), Isl1, Neurod1, Pax6 and $N k x 6-1$, whereas no expression of $n g n 3, P a x 4, N k x 2-2$, or Ptfla was observed (Fig. 2c). Pdx-1 was detected in the b

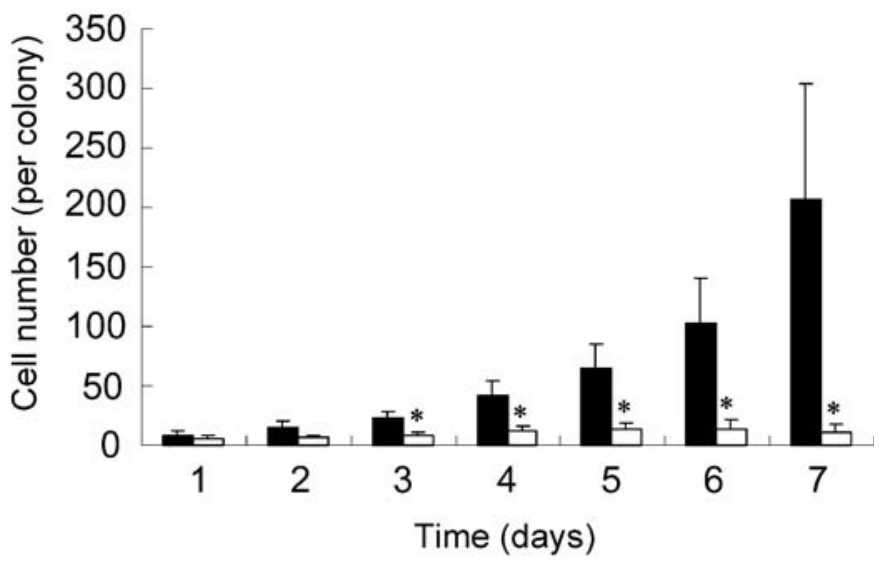

$1 \mathrm{mmol} / \mathrm{l}$ 8-Br-cAMP to the serum-free medium promoted cell proliferation (open bar; $n=37$ ), which was significantly prevented by $25 \mu \mathrm{mol} / 1$ PD98059 (hatched bar; $n=37$ ). ${ }^{*} p<0.0001$. Treatment with $3 \mu \mathrm{mol} / 1 \mathrm{KT} 5720$ (stippled bar; $n=39$ ) prevented the cell proliferation stimulated by $100 \mathrm{ng} / \mathrm{ml} \mathrm{CTx}$ (closed bar; $n=39$ ). $\# p<0.0001$ by twotailed Student's $t$-test. Error bars show SD nuclei of the most of the cells by immunocytochemistry (Fig. 2d). Western blot analysis detected the Pdx-1 protein of $46 \mathrm{kDa}$ in these cells and also in MIN6 cells, a mouse insulinoma-derived beta cell line (Fig. 2e), although the amount of Pdx-1 protein was lower in the pancreatic ductderived cells than in the MIN6 cells. These results suggested that the cells we isolated were probably derived from pancreatic ductal epithelial cells, but were different from normal pancreatic duct epithelial cells in their gene expression pattern. Thus we designated these pancreatic cells as Pdx-1-positive pancreatic duct-derived (PPPD) cells.

Differentiation into the pancreatic endocrine and exocrine lineage

We established clonal lines of PPPD cells by limiting dilution under serum-free conditions. We established five 
a

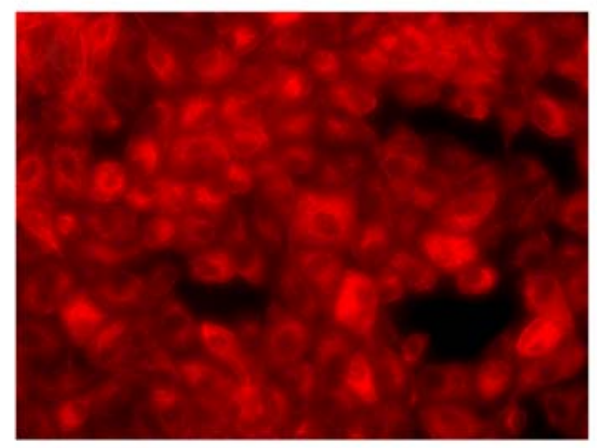

C

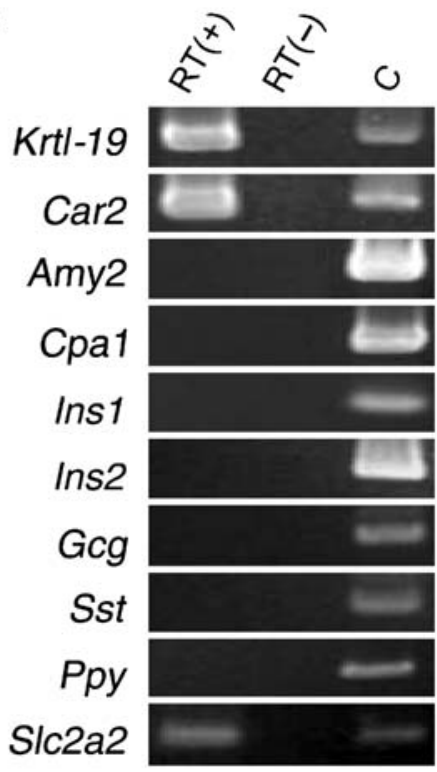

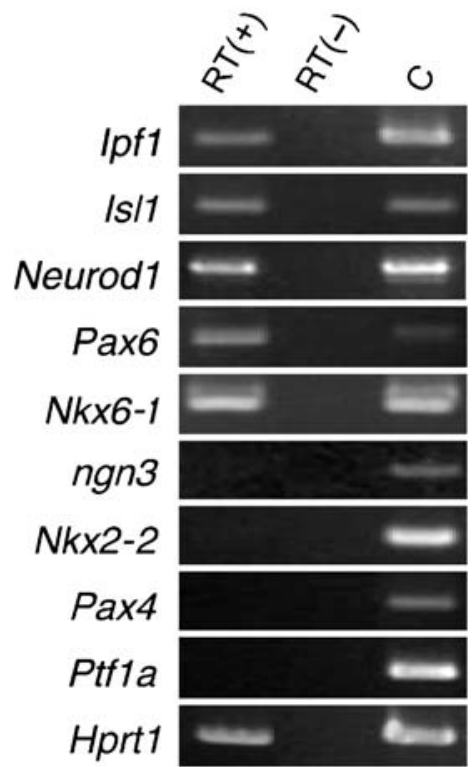

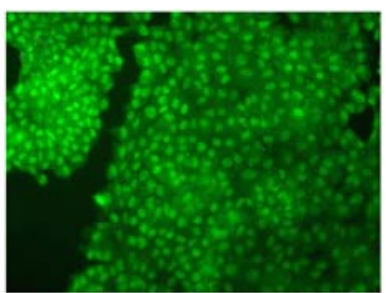

e

$46 \mathrm{kDa}$

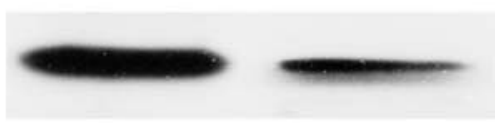

MIN6 cells

PPPD cells
Fig. 2 Characterisation of PPPD cells. a Immunostaining with an anti-pancytokeratin antibody. bi Transmission electron microscopy of PPPD cells revealed typical features of simple cuboidal epithelium. bii, biii The plasma membrane possessed typical specialisations. biv Two nuclei were eccentrically located and irregularly shaped. c RT-

PPPD clones: clone-2, $-3,-10,-11$ and -12 . We used these subclones to examine the effects of the transient expression of transcription factor genes. We infected clone-12 cells with an adenovirus vector expressing $n g n 3$ and $E g f p$ (Fig. 3a). The infection efficiency was approximately 30 $40 \%$ as assessed by GFP expression. Seven days after infection, the gene expression pattern of infected cells was analysed by RT-PCR. The results showed that the expression of islet hormone genes Ins 1, Ins2, Iapp and Sst (encoding somatostatin) was markedly elevated together with downstream targets of ngn3, such as Neurod1, Isl1, Pax4 and $N k x 2-2$, but not $N k x 6-1$ (Fig. 3b). Although total Ins 2 mRNA expression levels in cells infected with $A d V$ $n g n 3$, as determined by real-time RT-PCR, were 35 -fold higher than those in infected cells with $A d V-E G F P$ $(p<0.05)$, the expression levels attained were no more than
PCR analysis of PPPD cells cultured in serum-free medium for 2 weeks. $R T$ Treatment with reverse transcriptase, $C$ positive control (MIN6 cells for Pax4, brain for $n g n 3$, and whole pancreas or islet cells for other genes). d Immunostaining with an anti-Pdx-1 antibody (green). e Western blot analysis with anti-Pdx-1 antibody

$0.05 \%$ of those in islets. Immunocytochemical analysis showed that only a few cells were positive for insulin or somatostatin staining (data not shown). Next we infected clone-2 cells with adenovirus vector expressing Ptfla (Fig. 3a). Seven days later, the infected cells were found to express the pancreatic exocrine genes Amy2 (encoding amylase) and Cpal (encoding carboxypeptidase A1) and the endocrine hormone gene Ppy (encoding pancreatic polypeptide) (Fig. 3c). These data showed that PPPD cells have the potency to differentiate into both pancreatic endocrine and exocrine cell lineages.

Differentiation into the hepatocyte-like cell lineage

PPPD cells could be maintained by repeated passages for more than 1 year without growth inhibition, not only in 
Fig. 3 Effects of adenovirusmediated expression of transcription factors in clonal cells. a The structure of the expression cassette integrated into the adenoviral vector. b,c RT-PCR analysis of $A d V-n g n 3$-infected clone-12 cells (b) or AdV-Ptflainfected clone-2 cells (c). c positive control (MIN6 cells for Pax4, brain for $n g n 3$, and whole pancreas or islet cells for other genes)
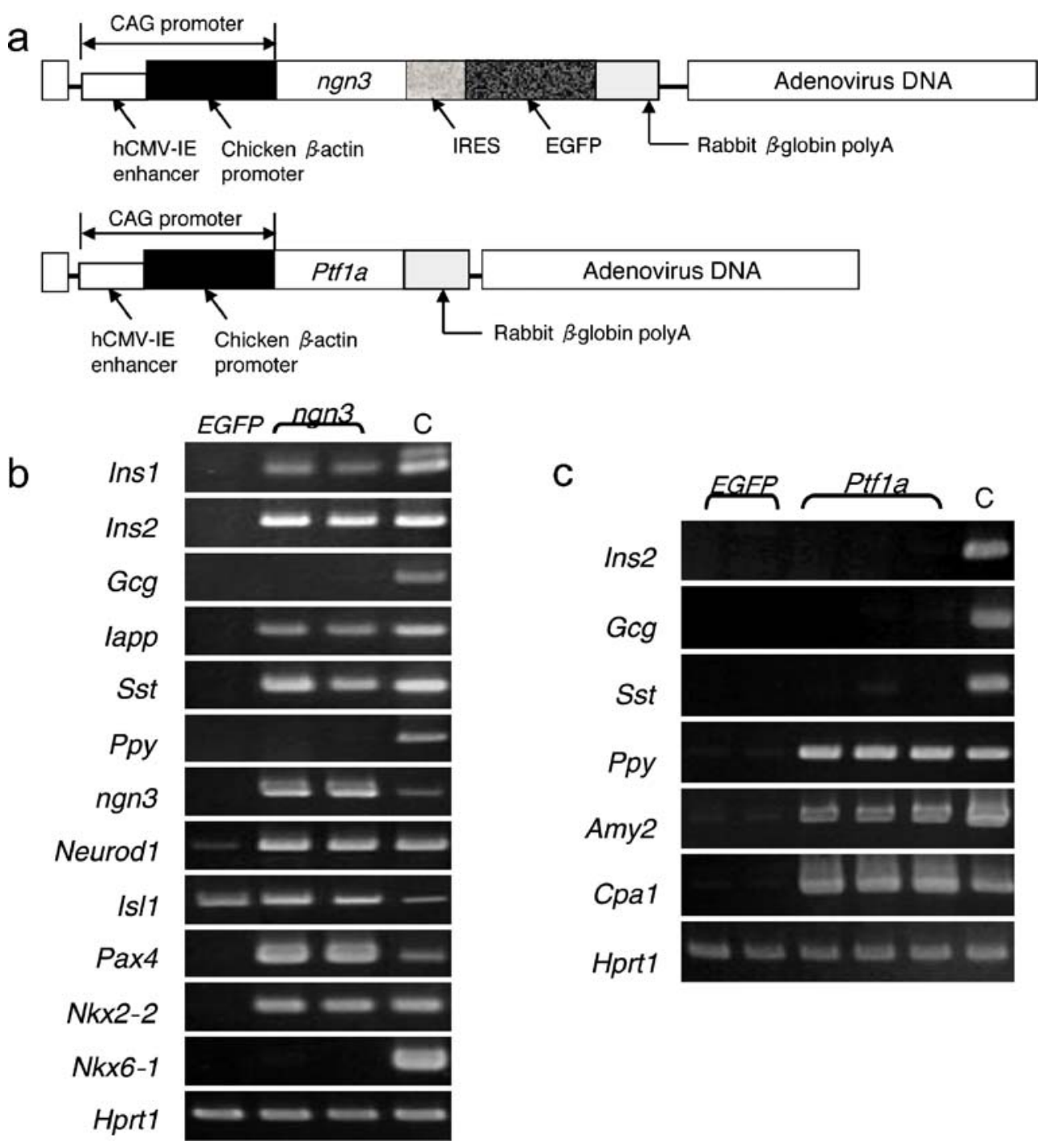

serum-free conditions but also in serum-containing conditions. The presence of FBS in the medium supported better cell proliferation. The addition of CTx was also essential for cell proliferation in serum-containing medium.

The effect of long-term culture with FBS on the characteristics of PPPD cells was examined by RT-PCR. At passage 16 in $10 \%$ FBS-containing medium, the mRNA expression of Ipf1, Neurodl and $N k x 6-1$ was markedly downregulated or lost (Fig. 4a). The mRNAs for Albl (albumin), Afp ( $\alpha$-fetoprotein), Hgf, Apcs (serum amyloid $\mathrm{P}$ component), Foxa2 (HNF3 $\beta$ ) and Onecut1 (HNF6) were markedly increased, whereas islet cell and acinar cell markers did not appear. By immunocytochemistry, most of the proliferating PPPD cells were stained in the cytoplasm with an anti-albumin antibody and in the nuclei with an anti-HNF3 $\beta$ antibody (Fig. 4bi-iii). The expression level of the albumin protein in each cell appeared to be positively correlated with the level of HNF3 $\beta$ staining.

Dexamethasone is reported to promote the conversion of AR42J cells, which were derived from a rat pancreatic acinar cell tumour, into hepatocytes [17]. To analyse the effect of dexamethasone, PPPD cells were incubated for 2 weeks with several concentrations of dexamethasone (Fig. 4c). RT-PCR analysis revealed that the expression levels of the Albl gene increased with dexamethasone in a dose-dependent manner. Thus, PPPD cells were shown to have the ability to differentiate into the hepatocyte-like cell lineage.

\section{Discussion}

In the present study, we established a feasible method for the long-term culture of pancreatic ductal epithelial cells from normal adult mice. Cell proliferation was maintained under serum-free conditions for more than 1 year after the isolation. The expansion from single cells in serum-free medium enabled us to establish several clonal cell lines. The establishment of serum-free culture conditions is considered to be very important for studies of cell 


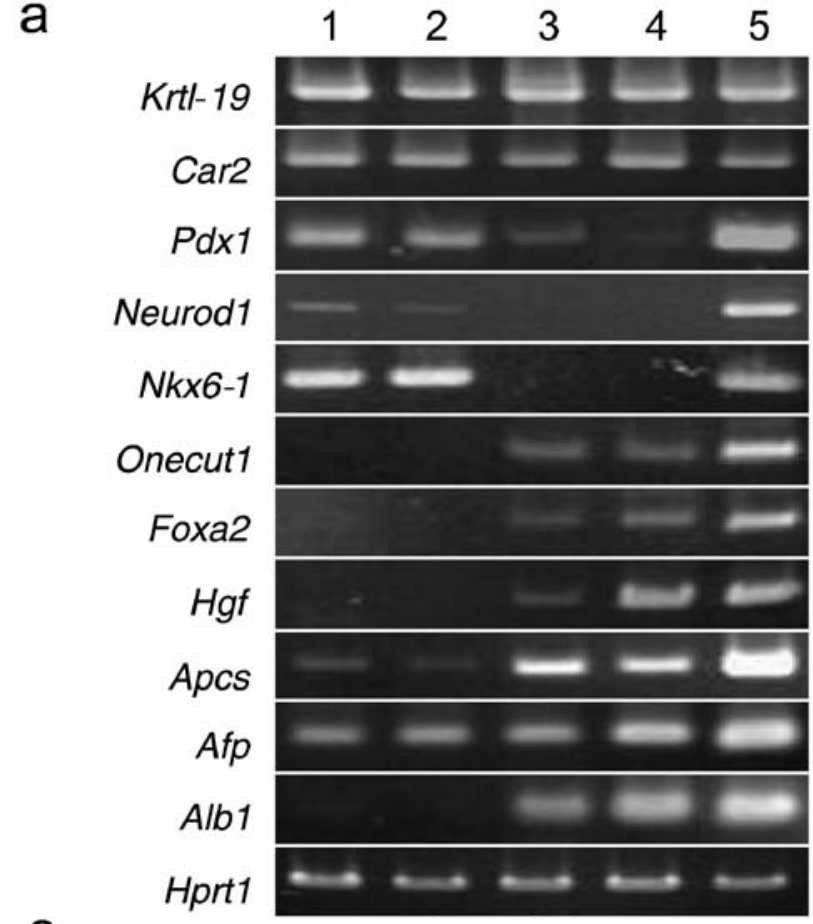

C

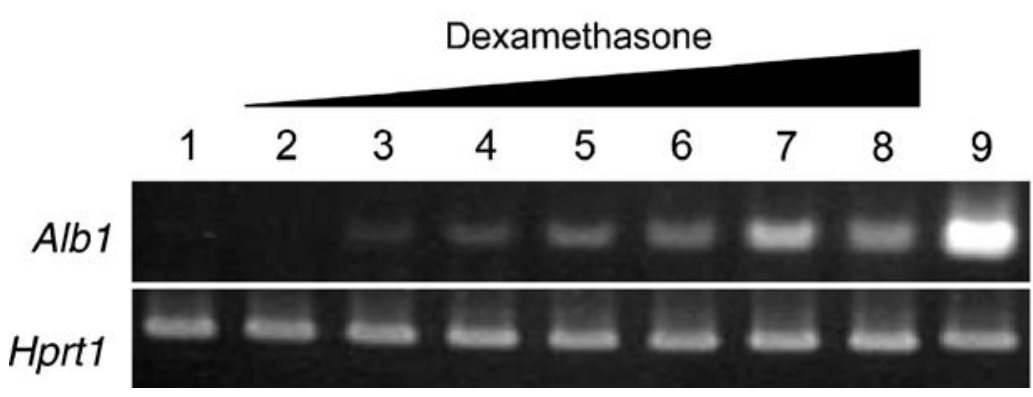

bi

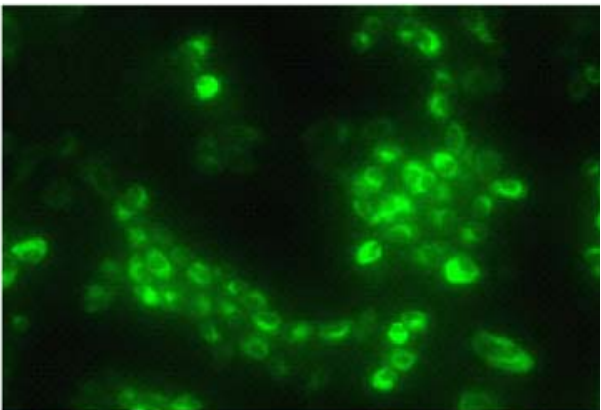

bii

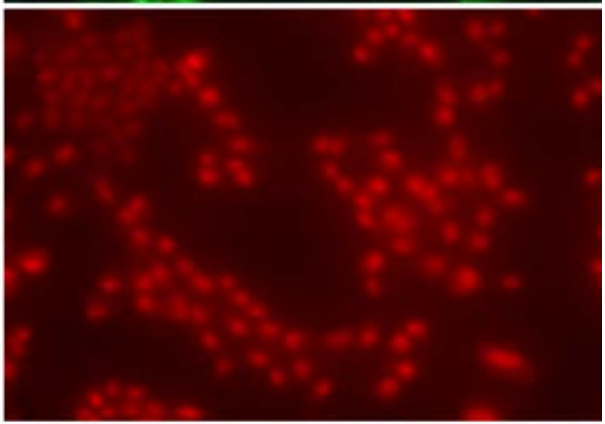

biii

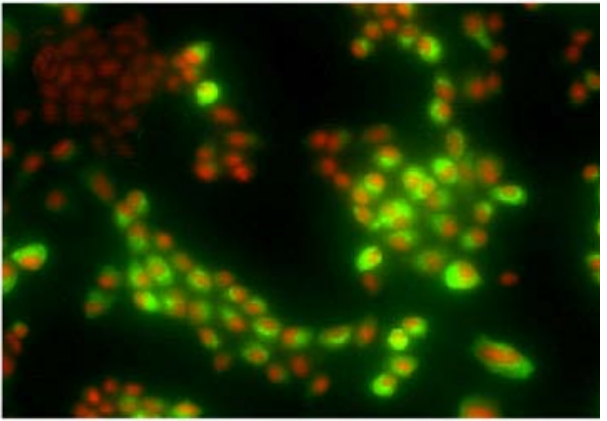

Fig. 4 Effect of long-term culture or addition of dexamethasone on PPPD cells. a RT-PCR analysis for PPPD cells after 10 months of culture in serum-free or $10 \%$ FBS-containing medium. Lane 1, passage 3 in serum-free medium; lane 2, passage 13 in serum-free medium; lane 3, passage 11 in FBS-containing medium; lane 4, passage 15 in FBS-containing medium; lane 5, positive control (whole pancreas, isolated islet or liver). bi, bii Immunostaining of PPPD cells

differentiation, because the factors that affect cell growth or differentiation can be identified without the effect of unknown factors contained in the FBS.

The presence of cAMP-elevating factors, like CTx, a bacterial toxin secreted by Vibrio cholerae, was crucial for the proliferation and maintenance of PPPD cells. Cyclic AMP reportedly promotes the growth of various kinds of isolated epithelial cells [18-25]. Recently, CTx was also used for the isolation of immortalised human breast epithelial cell lines with stem cell properties [25]. Our experiments using pharmacological agents that specifically target different aspects of cAMP-dependent signalling, 8Br-cAMP, CTx, PKA inhibitor and MAPK inhibitor, further supported the idea that the proliferation of pancreatic ductal at passage 16 with an anti-albumin antibody (green) and with an antiHNF3 $\beta$ antibody (red). biii Merge of both images. $\mathbf{c}$ RT-PCR analysis of albumin gene expression in PPPD cells treated with different concentrations of dexamethasone. Lane 1, no treatment; lane 2, $10 \mathrm{pmol} / 1$; lane 3, $100 \mathrm{pmol} / \mathrm{l}$; lane 4, $1 \mathrm{nmol} / \mathrm{l}$; lane 5, $10 \mathrm{nmol} / 1$; lane $6,100 \mathrm{nmol} / 1$; lane $7,1 \mu \mathrm{mol} / 1$; lane $8,10 \mu \mathrm{mol} / 1$; lane 9, positive control (adult mouse liver)

epithelial cells is promoted by the cAMP signalling pathway.

Pdx-1 is detected in all embryonic protodifferentiated epithelial cells during pancreatic development [26]. Several studies have demonstrated that adult pancreatic ductal cells that retain the capacity for proliferation re-express Pdx-1 in the course of islet differentiation and regeneration [27, 28]. In the present study, Pdx-1 protein was detected in the nuclei of most of the PPPD cells by immunocytochemistry and immunoblot analysis. These observations suggest that PPPD cells derived from the adult mouse pancreas have the potential to differentiate into islet endocrine cells.

In the present study, PPPD cells were converted into cells expressing Ins1, Ins 2 and Sst (somatostatin) genes by 
the adenovirus-mediated expression of $n g n 3$, consistent with the report that neuroendocrine differentiation markers including insulin were induced in adult human pancreatic duct cells by adenovirus-mediated overexpression of $n g n 3$ [29]. These results suggest that $n g n 3$ expression is critical for regeneration of pancreatic endocrine cells. Infection with Ptfla-expressing adenovirus vector induced the expression of genes for Amy2, Cpal and PPy in PPPD cells. Thus, Ptfla is essential for the induction of pancreatic exocrine enzymes. Although the molecular mechanisms that underlie the induction of $P P$ are uncertain, this result is intriguing. Only a few cells were positively stained for insulin, somatostatin, or CXPA by immunocytochemistry. One of the possible reasons for this is that the infection efficiency of adenovirus vector was not good in PPPD cells. Another possibility is that a single transcription factor gene might not be enough for the induction of pancreatic endocrine hormones or exocrine enzymes. A study is in progress to improve the efficiency of differentiation into insulin-positive cells.

Adenovirus-mediated transduction experiments were repeatedly conducted in all five clones. Interestingly, Ins I and Ins 2 mRNA induction in clone-12 by the treatment with $A d V-n g n 3$, and both $A m y 2$ and Cpal mRNA induction in clone-2 by the treatment with AdV-Ptfla were most prominent (data not shown). These results suggest that PPPD cells were composed of a heterogeneous population. In fact, there were some differences among five clones in the expression pattern of several pancreatic transcription factors, Isl1, Neurod1, Pax-6 and Nkx6-1, which parental PPPD cells moderately expressed (data not shown). We propose that pancreatic ductal epithelium contains heterogeneous precursor cells that have distinct characteristics in terms of transcriptional regulation.

In embryonic development, it appears that there is a common precursor for the hepatic and pancreatic lineages [30]. The conversion of pancreas to liver has also been described in experimental models both in vivo and in vitro $[7,17]$. After long-term culture of PPPD cells in serumcontaining medium, hepatocyte markers were upregulated, while pancreatic transcription factor genes were downregulated in PPPD cells. Alb1 mRNA expression was also dose-dependently induced by treatment with dexamethasone. However, other mature liver markers, such as PckI (phosphoenolpyruvate carboxykinase), G6pc (glucose-6phosphatase), Tat (tyrosine aminotransferase) and Otc (ornithine transcarbamylase) were undetectable by RTPCR analysis (data not shown). Therefore, the albuminproducing PPPD cells are not mature hepatocytes. Our culture conditions may not be optimal for obtaining complete hepatocyte differentiation.

The next important point of this report is whether PPPD cells were truly derived from pancreatic duct cells or not.
Recent studies used a lineage tracing system to demonstrate that explant cultures of pancreas developed the acinar-toductal transdifferentiation of mature exocrine cells in response to EGF receptor signalling [31]. Baeyens et al. demonstrated by in vitro culture experiment that insulinproducing cells were generated from pancreatic exocrine cells via the acinar-to-ductal transdifferentiation [32]. This conclusion was based on the existence of the cells that were binucleated and coexpressed amylase with cytokeratin 20 . In our experiment, only some of the cultured cells coexpressed amylase and cytokeratin after the first $24 \mathrm{~h}$ in serum-free conditions (data not shown) and exhibited binuclearity, a characteristic of part of acinar cells by ultrastructural study. These amylase-positive cells were lost within a few weeks, and gene expression of pancreatic endocrine markers as well as exocrine markers became undetectable by RT-PCR analysis after first passage in serum-free conditions. Therefore, it does not seem likely that PPPD cells were derived from cell-types other than pancreatic ductal cells.

In conclusion, we established a reliable method for isolating pancreatic epithelial ductal cells from adult normal mouse pancreas. The presence of intracellular cAMP elevating factors was crucial to the proliferation and maintenance of pancreatic epithelial cells under both serum-free and serum-containing culture conditions. We also demonstrated that the cells designated as PPPD cells give rise not only to pancreatic endocrine and exocrine cells but also to albumin-producing cells. PPPD cells should allow us to investigate the precise molecular mechanisms involved in the differentiation of pancreatic ductal cells into insulin-producing cells and offer promise for a non-invasive therapy for type 1 diabetes and liver cirrhosis.

Acknowledgements This work was supported by grants from the Japanese Ministry of Education, Science, Sports and Culture and from the Prefecture Collaboration of Regional Entities for the Advancement of Technological Excellence, Japan Science and Technology Corporation. The authors declare that they have no duality of interest.

\section{References}

1. Bonner-Weir S, Baxter LA, Schuppin GT, Smith FE (1993) A second pathway for regeneration of adult exocrine and endocrine pancreas: a possible recapitulation of embryonic development. Diabetes 42:1715-1720

2. Wang RN, Kloppel G, Bouwens L (1995) Duct- to islet-cell differentiation and islet growth in the pancreas of duct-ligated adult rats. Diabetologia 38:1405-1411

3. Gu D, Sarvetnick N (1993) Epithelial cell proliferation and islet neogenesis in IFN-gamma transgenic mice. Development 118:33-46

4. Song SY, Gannon M, Washington MK et al (1999) Expansion of Pdx1-expressing pancreatic epithelium and islet neogenesis in transgenic mice overexpressing transforming growth factor $\alpha$. Gastroenterology 117:1416-1426 
5. Ramiya VK, Maraist M, Arfors KE, Schatz DA, Peck AB, Cornelius JG (2000) Reversal of insulin-dependent diabetes using islets generated in vitro from pancreatic stem cells. Nat Med 6:278-282

6. Bonner-Weir S, Taneja M, Weir GC, Tatarkiewicz K, Song KH, Sharma A (2000) In vitro cultivation of human islets from expanded ductal tissue. Proc Natl Acad Sci USA 97:7999-8004

7. Wang X, Al-Dhalimy M, Lagasse E, Finegold M, Grompe M (2001) Liver repopulation and correction of metabolic liver disease by transplanted adult mouse pancreatic cells. Am J Pathol 158:571-579

8. Githens S, Schexnayder JA, Moses RL, Denning GM, Smith JJ, Frazier ML (1994) Mouse pancreatic acinar/ductular tissue gives rise to epithelial cultures that are morphologically, and functionally indistinguishable from interlobular duct cell cultures. In Vitro Cell Dev Biol 30A:622-635

9. Tsao MS, Duguid WP (1987) Establishment of propagable epithelial cell lines from normal adult rat pancreas. Exp Cell Res 168:365-375

10. Hubchak S, Mangino MM, Reddy MK, Scarpelli DG (1990) Characterization of differentiated Syrian golden hamster pancreatic duct cells maintained in extended monolayer culture. In Vitro Cell Dev Biol 26:889-897

11. Sato T, Sato M, Hudson EA, Jones RT (1983) Characterization of bovine pancreatic ductal cells isolated by a perfusion-digestion technique. In Vitro 19:651-660

12. Verme TB, Hootman SR (1990) Regulation of pancreatic duct epithelial growth in vitro. Am J Physiol 258:G833-G840

13. Trautmann B., Schlitt HJ, Hahn EG, Lohr M (1993) Isolation, culture, and characterization of human pancreatic duct cells. Pancreas 8:248-254

14. Moritoh Y, Yamato E, Yasui Y, Miyazaki S, Miyazaki J-I (2003) Analysis of insulin-producing cells during in vitro differentiation from feeder-free embryonic stem cells. Diabetes 52:1163-1168

15. Tashiro F, Niwa H, Miyazaki J (1999) Constructing adenoviral vectors by using the circular form of the adenoviral genome cloned in a cosmid and the Cre-loxP recombination system. Hum Gene Ther 10:1845-1852

16. Bastiaen PIH, Majoul IV, Verveer PJ, Söling HD, Jovin TM (1996) Imaging the intracellular trafficking and state of the AB5 quaternary structure of cholera toxin. EMBO J 15:4246-4253

17. Shen CN, Slack JMW, Tosh D (2000) Molecular basis of transdifferentiation of pancreas to liver. Nat Cell Biol 2:879-887

18. Dugan LL, Kim JS, Zhang Y et al (1999) Differential effects of cAMP in neurons and astrocytes. J Biol Chem 274:25842-25848

19. Fujita T, Meguro T, Fukuyama R, Nakamura H, Koida M (2002) New signaling pathway for parathyroid hormone and cyclic AMP action on extracellular-regulated kinase and cell proliferation in bone cells. J Biol Chem 277:22191-22200
20. Schmidt CM, McKillop IH, Cahill PA, Sitzmann JV (1999) The role of cAMP-MAPK signaling in the regulation of human hepatocellular carcinoma growth in vitro. Eur J Gastroenterol Hepatol 11:1393-1399

21. Pittelkow MR, Shipley GD (1989) Serum-free culture of normal human melanocyte: growth kinetics and growth factor requirements. J Cell Physiol 140:565-576

22. Kapas S, Hagi-Pavli E, Brown DW, Chhajlani V, Farthing PM (1998) Direct effects of corticotrophin on oral keratinocyte cell proliferation. Eur J Biochem 256:75-79

23. Rosenfield RL, Wu PP, Ciletti N (2002) Sebaceous epithelial cell differentiation requires cyclic adenosine monophosphate generation. In Vitro Cell Dev Biol 38:54-57

24. Depoortere F, Pirson I, Bartek J, Dumont JE, Roger PP (2000) Transforming growth factor $\beta 1$ selectively inhibits the cyclic AMP-dependent proliferation of primary thyroid epithelial cells by preventing the association of cyclin D3-cdk4 with nuclear p2 $7^{\text {kip1. }}$. Mol Biol Cell 11:1061-1076

25. Gudjonsson T, Villadsen R, Nielsen HL, Ronnov-Jessen L, Bissell MJ, Petersen OW (2002) Isolation, immortalization, and characterization of a human breast epithelial cell line with stem cell properties. Genes Dev 16:693-706

26. Jonsson, J, Carlsson L, Edlund T, Edlund H (1994) Insulin promoter-factor 1 is required for pancreas development in mice. Nature 371:606-609

27. Sharma A, Zangen DH, Reitz P et al (1999) The homeodomain protein Idx-1 increases after an early burst of proliferation during pancreatic regeneration. Diabetes 48:507-513

28. Gmyr V, Kerr-Conte J, Belaich S et al (2000) Adult human cytokeratin 19-positive cells reexpress insulin promoter factor 1 in vitro: further evidence for pluripotent pancreatic stem cells in humans. Diabetes 49:1671-1680

29. Heremans Y, Van De Casteele M, in't Veld P et al (2002) Recapitulation of embryonic neuroendocrine differentiation in adult human pancreatic duct cells expressing neurogenin3. J Cell Biol 159:303-311

30. Deutsch G, Jung J, Zheng M, Lora J, Zaret KS (2001) A bipotential precursor population for pancreas and liver within the embryonic endoderm. Development 128:871-881

31. Means AL, Meszoely IM, Suzuki K et al (2005) Pancreatic epithelial plasticity mediated by acinar cell transdifferentiation and generation of nestin-positive intermediates. Development 132:3767-3776

32. Baeyens L, De Breuck S, Lardon J, Mfopou JK, Rooman I, Bouwens L (2005) In vitro generation of insulin-producing beta cells from adult exocrine pancreatic cells. Diabetologia 48:49-57 